\title{
The Action of Lung Lysosomal Phospholipases on Dipalmitoyl Phosphatidylcholine and its Significance for the Synthesis of Pulmonary Surfactant
}

\author{
M. F. Heath ${ }^{(46)}$ and W. Jacobson \\ Strangeways Research Laboratory, Cambridge, United Kingdom
}

\section{Summary}

Subcellular fractions were prepared from rabbit lung and characterized by marker enzyme assays. Phospholipases $A$ of lysosomal type (active at $\mathrm{pH} 4.0$ in the absence of $\mathrm{Ca}^{2+}$ ) show a peak of specific activity in fraction P3 $(13000 \times g ; 20 \mathrm{~min}$; pellet). About $70 \%$ of the phospholipase $A$ activity of $P 3$ can be obtained in a soluble extract. The rates of hydrolysis of dipalmitoyl (saturated) and unsaturated phosphatidylcholine molecules, presented to enzyme preparations in liposomes of varying composition, are shown in Tables 3 to 5 . Although the rate for unsaturated molecules is unaffected by liposome composition, saturated molecules are hydrolyzed significantly faster in 5 mol \% dipalmitoyl phosphatidylcholine liposomes than in 95 mol \%. With enzyme preparation I $\left(60 \% A_{1} ; 40 \% A_{2}\right)$ the increase was 6-fold $(P<0.01)$. Preparations I and II hydrolyzed both kinds of molecules at similar rates in 50 mol \% dipalmitoyl phosphatidylcholine liposomes, but preparation III, with a higher proportion of $A_{2}(80 \%)$, gave a notably lower rate of hydrolysis of saturated molecules. Phosphatidylglycerol (10 mol \%) also decreased the rate of hydrolysis of saturated molecules. These results are discussed in relation to fluidity of the liposomes and to the functions of the lysosomal-type phospholipases $A$ of the lamellar inclusion bodies of the lung.

\section{Speculation}

In lamellar bodies, phospholipase $\mathbf{A}_{2}$ will preferentially hydrolyze unsaturated phosphatidylcholine, yielding a lysolipid which can be reacylated to produce dipalmitoyl phosphatidylcholine; phospholipase $A_{1}$ will require further inhibition, possibly provided by the phosphatidylglycerol of surfactant. Failure of $A_{2}$ action or failure of the inhibition of $A_{1}$ would be expected to lead to a deficiency of surfactant and thus to the respiratory distress syndrome in the newborn.

Pulmonary surfactant, the agent that maintains the stability of the alveoli of the lung against collapse, is a mixture of lipids with a small amount of protein. The principal lipid, comprising at least $40 \%$ of the total, is 1,2-dipalmitoyl phosphatidylcholine $(15,22)$. Most mammalian phosphatidylcholines have at least one unsaturated fatty acid residue (at position 2 ), but this major component of surfactant has two saturated acids. This unusual composition is necessary for its surfactant function (40). The respiratory distress syndrome of the newborn (hyaline membrane disease) results from a deficiency of pulmonary surfactant $(4,13,20)$.

The source of the extracellular surfactant is to be found in the lamellar inclusion bodies of the cuboidal (type II) pneumonocytes of the alveolar epithelium $(4,9,13,20,21)$. Cytochemical studies on lung sections and enzyme assays performed on isolated lamellar body preparations have shown the presence in these inclusions of numerous lysosomal hydrolases (16). The origin and purpose of this lysosomal involvement is unsure, but it seems likely that lysosomes take up newly synthesized surfactant by an autophagic mechanism and process it to the characteristic lamellar bodies before it is released from the cell by exocytosis $(16,34,36)$.

The lysosomal hydrolases present in lamellar bodies include two enzymes capable of catabolizing the phosphatidylcholine of surfactant, phospholipases $A_{1}$ (EC 3.1.1.32) and $A_{2}$ (EC 3.1.1.4) (17). Phospholipase $A_{1}$ hydrolyzes the fatty acid residue at position 1 of phosphatidylcholine and other phospholipids; phospholipase $\mathrm{A}_{2}$ removes the acid at the 2-position. The lysosomal forms of these enzymes have maximum activity near $\mathrm{pH} 4$, are inhibited by $\mathrm{Ca}^{2+}$, and require the phospholipid for hydrolysis to be in the form of a bilayer, such as the lamellae of the lung inclusion bodies or the liposomes (lipid vesicles) used as the assay substrate.

Aside from their catabolic role, these enzymes could function in the normal process of surfactant biosynthesis. The lysosomal phospholipase $\mathbf{A}_{2}$ of the lamellar bodies in particular may be concerned with the remodeling of unsaturated phosphatidylcholine into the dipalmitoyl species by removing the unsaturated fatty acid from the 2-position so that it may be replaced with a palmitoyl residue (37).

Under normal conditions, the dipalmitoyl phosphatidylcholine is not degraded by these enzymes, but under abnormal conditions, the situation could arise where surfactant is synthesized at a normal rate, but is broken down intracellularly by phospholipases before it can be released to the alveolar space. This paper describes the preparation of soluble lysosomal phospholipases from rabbit lung, gives an analysis of their action on dipalmitoyl and unsaturated phosphatidylcholines presented to the enzymes as liposomes of mixed composition, and discusses the relevance of these findings to the roles of phospholipases $A$ in the normal and pathologic metabolism of pulmonary surfactant.

\section{MATERIALS AND METHODS}

\section{PREPARATION OF A LYSOSOMAL FRACTION FROM RABBIT LUNG}

Lungs from New Zealand White rabbits were homogenized in cold $0.25 \mathrm{M}$ sucrose in $50 \mathrm{mM}$ Tris- $\mathrm{HCl}(\mathrm{pH} \mathrm{7})(10 \mathrm{ml} / \mathrm{g})$ for 2 $\times 30 \mathrm{sec}$ with a Silverson homogenizer (Silverson Machines Ltd., London, United Kingdom), and the homogenate was filtered through four layers of muslin. A scheme of differential centrifugation was then applied as follows (see Table 1): $600 \times \mathrm{g}, 10 \mathrm{~min}$ to yield pellet Pl consisting of cell debris and nuclei; $5000 \times \mathrm{g}, 20$ min giving P2, mitochondrial fraction; $13000 \times \mathrm{g}, 20 \mathrm{~min}$ giving $\mathrm{P}$, lysosomal fraction; $40,000 \times \mathrm{g}, 30 \mathrm{~min}$ giving $\mathrm{P} 4$, microsomal fraction, and the final supernatant, $S$. All pellets were resuspended in $1 \mathrm{mM}$ disodium EDTA in $1 \mathrm{mM} \mathrm{NaHCO}$. All fractions and a sample of the homogenate were subjected to five cycles of freezing and thawing and then dialyzed overnight against $1 \mathrm{mM}$ EDTA:1 
$\mathrm{mM} \mathrm{NaHCO}$. These fractions were analyzed for protein content and characterized by assays of marker enzymes.

\section{ANALYSIS OF LUNG FRACTIONS}

Protein was estimated by the procedure of Lowry et al. (25) as modified by Campbell and Sargent (7) with bovine serum albumin as standard (Armour Pharmaceutical Co., Chicago, IL). Lysosomal acid phosphatase (EC 3.1.3.2) was determined as that activity sensitive to inhibition by tartrate (see Ref. 3), with 4-nitrophenyl phosphate as substrate (Sigma Technical Bulletin 104; Sigma London Chemical Co. Ltd., Poole, Dorset, United Kin\}. Cathepsin D (EC 3.4.23.5) was assayed according to Barrett (2) with bovine hemoglobin (gift of Dr. A. J. Barrett) as substrate. Total arylsulphatase (EC 3.1.6.1) was determined by the method of Worwood et al. (42) which yields a combined value for arylsulphatases $A$ and $B$. The substrate was 2-hydroxy-5-nitrophenyl sulphate (Sigma London Chemical Co. Ltd.). Succinate dehydrogenase (EC 1.3.99.1) was assayed according to Pennington (29) as modified by Porteous and Clark (31). NADPH cytochrome reductase (EC 1.6.2.4) was assayed with cytochrome c (Sigma London Chemical Co. Ltd.) as acceptor (30). Lactate dehydrogenase (EC 1.1.1.27) was determined according to Sigma Technical Bulletin 340-UV.

\section{PREPARATION OF EXTRACT CONTAINING LYSOSOMAL PHOSPHOLIPASES}

After freezing and thawing and dialysis of fraction P3 from rabbit lung, soluble phospholipases $A$ were recovered by centrifugation at $90000 \times \mathrm{g}$ for $2 \mathrm{hr}$. The soluble extract of P3 was dialyzed against $20 \mathrm{mM}$ Tris- $\mathrm{HCl}$ ( $\mathrm{pH} 7.5$ ), applied to a column $(1.5 \times 32 \mathrm{~cm})$ of Ultrogel AcA54 (LKB Instruments Ltd., Croydon, United Kingdom), and eluted with this buffer. Fractions of $1 \mathrm{ml}$ were collected.

\section{PHOSPHOLIPASE ASSAYS}

The assay of lysosomal phospholipases $A_{1}$ (EC 3.1.1.32) and $A_{2}$ (EC 3.1.1.4) in rabbit lung fractions was performed as previously described $(17,43)$, except that an improved chromatographic system was used: hexane:chloroform:methanol:acetic acid:water, $100: 75: 25: 2: 1, \mathrm{v} / \mathrm{v}$. Sensitivity to inhibition by $\mathrm{Ca}^{2+}$ ions was investigated in $0.1 \mathrm{M}$ sodium acetate buffer ( $\mathrm{pH} 4.0$ ) containing either $5 \mathrm{mM}$ disodium EDTA or $20 \mathrm{mM}$ calcium acetate. Incubations were also carried out in $0.1 \mathrm{M}$ Tris- $\mathrm{HCl}\left(\mathrm{pH} 9.0\right.$ at $37^{\circ} \mathrm{C}$ ) containing $5 \mathrm{mM} \mathrm{CaCl}_{2}$ to determine nonlysosomal phospholipases $A_{1}$ and $A_{2}$.

For assays on column eluates, the substrate was 1-palmitoyl-2$\left[1 .{ }^{14} \mathrm{C}\right]$ oleoylglycerophosphocholine $(55 \mathrm{Ci} / \mathrm{mole})$ (Applied Science Laboratories, State College, PA) diluted to $0.50 \mathrm{Ci} / \mathrm{mole}$ with Sigma type III-E phosphatidylcholine. Assay conditions were similar to those described for lysosomal enzymes above, except that $0.1 \mathrm{ml}$ of column fraction was incubated in a final volume of $0.2 \mathrm{ml}$.

The investigations of the activity of the enzymes against dipalmitoyl and unsaturated phosphatidylcholines were carried out with $1,2-\mathrm{di}-\left[1-{ }^{14} \mathrm{C}\right]$ palmitoyl-glycerophosphocholine $(88 \mathrm{Ci} / \mathrm{mole})$ and $\left[U-{ }^{14} \mathrm{C}\right]$ phosphatidylcholine (from Chlorella pyranoidosa: 1765 $\mathrm{Ci} /$ mole) (both from NEN Chemicals $\mathrm{GmbH}$, Dreieichenhain,

Table 1. Protein content of fractions from rabbit lung

\begin{tabular}{lc}
\hline \multicolumn{1}{c}{ Fraction } & $\begin{array}{c}\text { Protein content } \\
\text { (\% of homogenate) }\end{array}$ \\
\hline P1 $600 \times g, 10$ min, pellet & 18 \\
P2 $5000 \times g, 20 \mathrm{~min}$, pellet & 3.9 \\
P3 $13000 \times g .20$ min, pellet & 1.9 \\
P4 $40000 \times g, 30 \mathrm{~min}$, pellet & 2.0 \\
S Final supernatant & 65 \\
Total recovery & 91 \\
\hline
\end{tabular}

West Germany), the latter diluted to $88 \mathrm{Ci} /$ mole with Sigma type III-E phosphatidylcholine (from egg). These preparations were then diluted to $1.0 \mathrm{Ci} /$ mole with either Sigma type III-E phosphatidylcholine or Sigma synthetic 1,2-dipalmitoyl phosphatidylcholine or a mixture of the two to produce substrates with different proportions of saturated and unsaturated phospholipid, namely 5 , $40,50,60$ and $95 \mathrm{~mol} \%$ dipalmitoyl phosphatidylcholine. The effect of phosphatidylglycerol on the hydrolysis of saturated and unsaturated phosphatidylcholines was investigated on mixtures of 9 parts of $50 \mathrm{~mol} \%$ dipalmitoyl phosphatidylcholine with I part (mole/mole) of phosphatidylglycerol (prepared from egg phosphatidylcholine by Lipid Products, Redhill, Surrey, United Kingdom). Liposomes of these substrates were prepared at a phospholipid concentration of $0.1 \mathrm{mM}$ in $80 \mathrm{mM}$ sodium acetate $(\mathrm{pH} 4.0)$ containing $10 \mathrm{mM}$ disodium EDTA, as follows. The lipids were dried from chloroform solution in a stream of $\mathrm{N}_{2}$. The buffer $\left(\mathrm{N}_{2}\right.$ flushed) was added, and the tube was warmed at $45^{\circ} \mathrm{C}$ for $5 \mathrm{~min}$. The contents of the tube were mixed by vortexing and then ultrasonicated for $1 \mathrm{~min}$ at $1.5 \mathrm{~A}$ in an MSE Ultrasonic Power Unit. After rewarming to $45^{\circ} \mathrm{C}$, the substrate was dispensed in 0.1 $\mathrm{ml}$ aliquots to tubes at $37^{\circ} \mathrm{C}$. The reaction was started by the addition of $0.1 \mathrm{ml}$ of enzyme preparation.

Incubation proceeded for $1 \mathrm{hr}$ at $37^{\circ} \mathrm{C}$ with continuous shaking, and then the reaction was stopped by the addition of $0.7 \mathrm{ml}$ of chloroform: methanol $(1: 2, v / v)$, and the lipids were extracted by the method of Bligh and Dyer (5). Fatty acids and phospholipids were separated by TLC in hexane:diethyl ether:acetic acid (69:29: $2, v / v)(12)$ on silica gel $G$ (Eastman Chromagram 13191 from Kodak Ltd., Liverpool, United Kingdom). The spots were excised, and the radioactivity was measured in toluene scintillant $(3.4 \mathrm{~g} /$ liter 2,5-diphenyloxazole and $0.05 \mathrm{~g} /$ liter 1,4-bis-(4-methyl-5phenyloxazolyl-2)-benzene, both from Sigma London Chemical Co. Ltd). The percentage of breakdown of labeled phospholipid was then determined, due allowance being made for differences in specific activity between substrate and product (17). If dipalmitoyl and unsaturated phosphatidylcholines were not distinguished by the enzymes, the percentage of breakdown of each species at fixed phospholipid and enzyme concentrations would always be the same, irrespective of liposome composition. Differences between mean values of percentage breakdown were examined for significance by Student's $t$ test.

\section{RESULTS}

\section{PREPARATION OF A LYSOSOMAL FRACTION FROM RABBIT LUNG}

Table 1 shows a typical protein distribution in fractions prepared from rabbit lung homogenate by differential centrifugation, and Figure 1 shows the profiles of marker enzymes. The profiles of succinate dehydrogenase and NADPH cytochrome reductase indicate that mitochondria and microsomes are concentrated in fractions P2 and P4, respectively. The lysosomal markers acid phosphatase and cathepsin D have highest specific activity in P3, but significant activity in $\mathrm{P} 2$ and P4. Arylsulphatase shows maximum specific activity in P2. Lysosomes thus appear to concentrate in P3 and to a lesser extent in P2 which also contains mitochondria. Phospholipases $\mathrm{A}$ of lysosomal type (active at $\mathrm{pH} 4.0$ in the absence of $\mathrm{Ca}^{2+}$ ) show a peak of activity in $\mathrm{P3}$, although much $A_{1}$ activity is found in the final supernatant. Lysosomal phospholipases $\mathrm{A}$, in contrast to nonlysosomal types, are sensitive to inhibition by $\mathrm{Ca}^{2+}(11,39)$, and Table 2 shows the differences in calcium sensitivity between the phospholipases from $\mathrm{P3}$ and $\mathrm{S}$ which suggest that the activity at $\mathrm{pH} 4.0$ in the supernatant is not principally of lysosomal origin. The distributions of phospholipases of the nonlysosomal type (active at $\mathrm{pH} 9.0$ in the presence of $\mathrm{Ca}^{2+}$ ) differ from those of the lysosomal enzymes and show peaks of activity in the microsomal fraction, P4.

\section{PREPARATION OF SOLUBLE LYSOSOMAL PHOSPHOLIPASES}

About $70 \%$ of the phospholipase $A$ activity of fraction P3 is obtained in the soluble extract after centrifugation. A typical 
elution profile of this material after application to Ultrogel AcA54 is shown in Figure 2. Fractions 28 to 31 provided Enzyme Preparation $I$, containing phospholipases $A_{1}$ and $A_{2}$ in the ratio 60:40. Other extracts gave slightly different profiles, and from two of these were obtained preparation II $\left(A_{1}: A_{2}=40: 60\right)$ and preparation III $\left(A_{1}: A_{2}=20: 80\right)$.

THE ACTION OF LYSOSOMAL PHOSPHOLIPASES A ON DIPALMITOYL

$$
\text { AND UNSATURATED PHOSPHATIDYLCHOLINES }
$$

The rates of hydrolysis of dipalmitoyl (saturated) and unsaturated phosphatidylcholine molecules presented to enzyme preparation $I$ in liposomes of varying composition are shown in Table 3. Whereas the rate for unsaturated molecules is unaffected by liposome composition, saturated species are hydrolyzed 6-fold faster in $5 \mathrm{~mol} \%$ dipalmitoyl phosphatidylcholine liposomes than in $95 \mathrm{~mol} \%(P<0.01)$. The trends in the center of the composition range were confirmed by enzyme preparation II (Table 4). Preparation III, which contained a higher proportion of phospholipase $A_{2}(80 \%)$, gave somewhat different results (Table 5), most notably the low rate of hydrolysis of saturated molecules in $50 \mathrm{~mol} \%$ dipalmitoyl phosphatidylcholine liposomes. The effect of $10 \mathrm{~mol}$ $\%$ phosphatidylglycerol on hydrolysis rates in $50 \mathrm{~mol} \%$ dipalmi-

Table 2. Inhibition of lung phospholipases $\mathrm{A}$ by $\mathrm{Ca}^{2+}$

\begin{tabular}{ccc}
\hline & \multicolumn{2}{c}{$\begin{array}{c}\text { Activity in the presence of } \mathrm{Ca}^{2+} \text { (\% of EDTA } \\
\text { control) }\end{array}$} \\
\cline { 2 - 3 } Fraction & Phospholipase $\mathrm{A}_{1}$ & Phospholipase $\mathrm{A}_{2}$ \\
\hline P3 & 0 & 36 \\
S & 87 & 81 \\
\hline
\end{tabular}
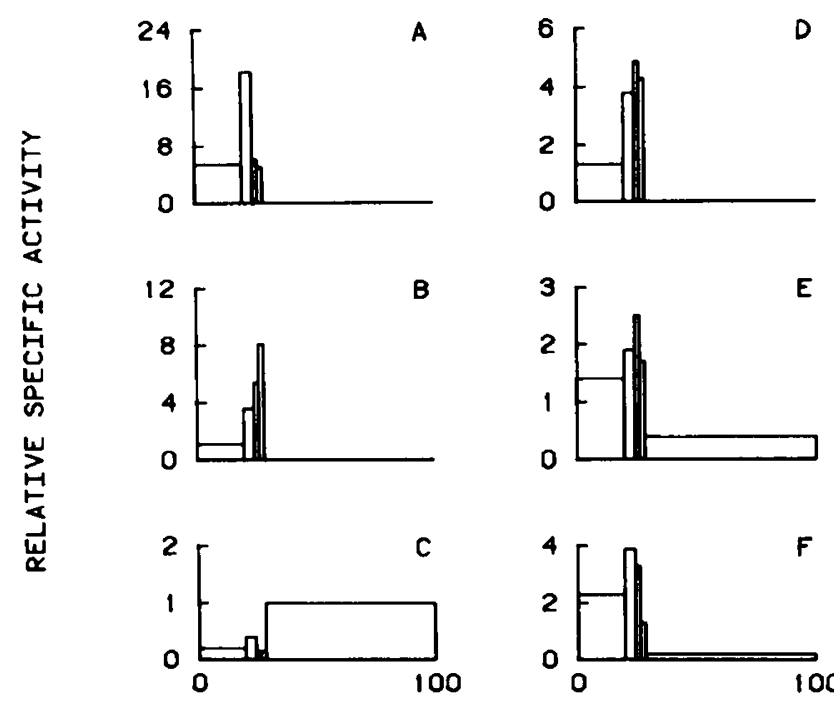

E
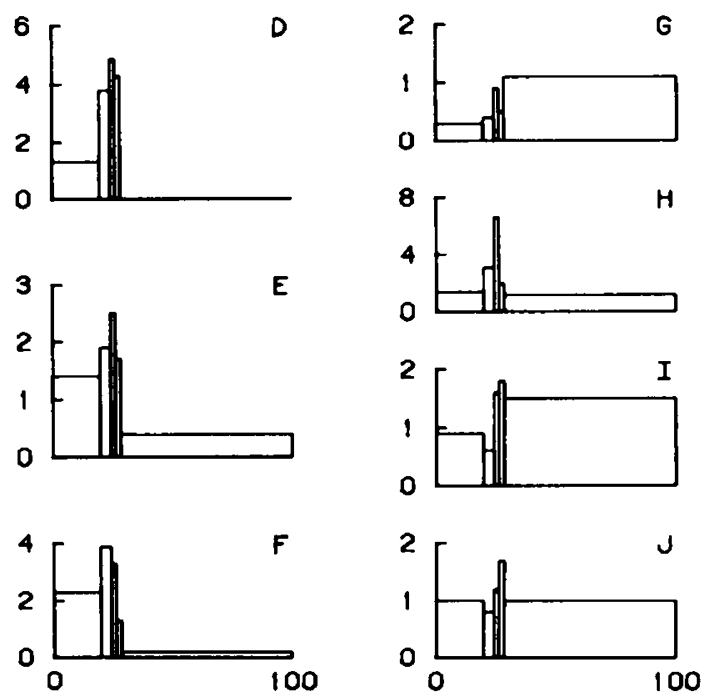

PER CENT TOTAL PROTEIN

Fig. 1. Enzyme profiles of rabbit lung fractions. Fractions were prepared and assayed as described in "Materials and Methods." Enzyme activities are expressed as relative specific activities (specific activity of fraction/specific activity of homogenate). $A$, succinate dehydrogenase; $B$, NADPH cytochrome reductase; $C$, lactate dehydrogenase; $D$, acid phosphatase; $E$, cathepsin $D ; F$, arylsulphatase; $G$, phospholipase $\mathrm{A}_{1}(\mathrm{pH} 4) ; H$, phospholipase $\mathrm{A}_{2}$ (pH 4); I, phospholipase $\mathrm{A}_{1}(\mathrm{pH} 9)$; J, phospholipase $\mathrm{A}_{2}$ (pH 9). Sequence of fractions: P1, P2, P3, P4, S.

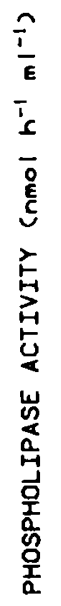

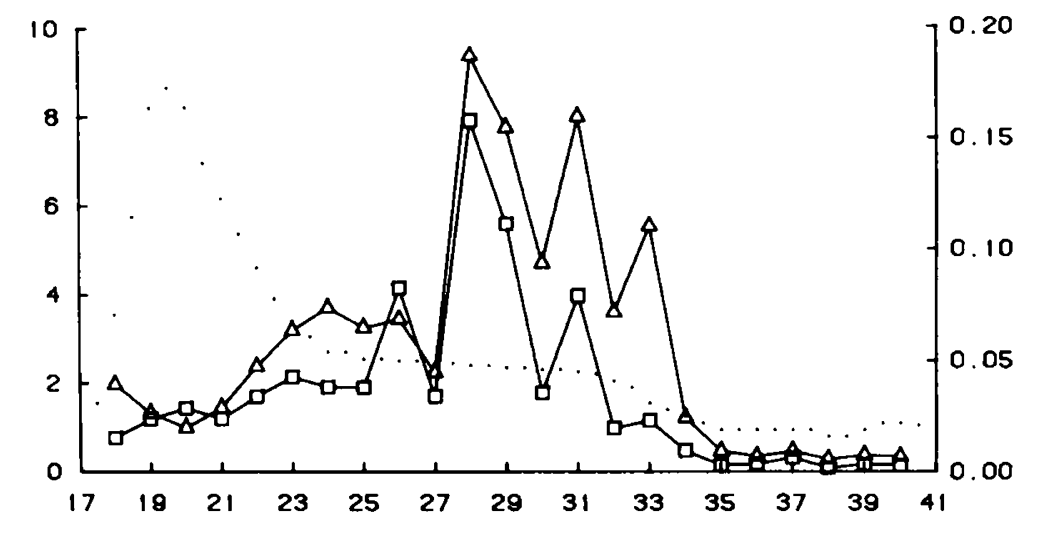

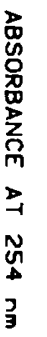

FRACTION NO.

Fig. 2. Gel chromatography of soluble lysosomal phospholipases $A$ from rabbit lung. The soluble extract of fraction $P 3$ was chromatographed on a 1.5- $\times 32-\mathrm{cm}$ column of Ultrogel AcA54 as described in "Materials and Methods." Fractions (1. $\mathrm{ml})$ were analyzed for phospholipases $A_{1}(\triangle)$ and $A_{2}$ $(\square)$ and monitored for protein content at $254 \mathrm{~nm}$ with a $3-\mathrm{mm}$ light path $(\cdots)$. The void volume elutes at fraction 18. 
Table 3. Rates of hydrolysis of saturated and unsaturated phosphatidylcholines presented to lung lysosomal phospholipases $A$ (preparation I) ${ }^{1}$ in liposomes of varying composition

\begin{tabular}{cccc}
\hline \multirow{2}{*}{$\begin{array}{c}\text { Liposome composition } \\
(\text { mol \% DPPC) }\end{array}$} & \multicolumn{2}{c}{ Rates of hydrolysis ${ }^{3}(\% / \mathrm{hr})$} & \\
\cline { 2 - 3 } & Saturated & Unsaturated & $P$ \\
\hline 5 & $16.44 \pm 2.30^{4}$ & $5.37 \pm 0.44$ & $<0.01$ \\
50 & $7.92 \pm 1.78$ & $6.87 \pm 2.79$ & NS $^{5}$ \\
95 & $2.64 \pm 1.42$ & $6.07 \pm 0.93$ & $<0.01$ \\
\hline
\end{tabular}

${ }^{\prime} A_{1}: A_{2}=60: 40$.

${ }^{2}$ Dipalmitoyl phosphatidylcholine.

${ }^{3} n=4$.

4 Mean \pm S.E.

${ }^{5}$ Not significant $(P>0.05)$

Table 4. Rates of hydrolysis of saturated and unsaturated phosphatidylcholines presented to lung lysosomal phospholipases $A$ (preparation II) ${ }^{1}$ in liposomes of varying composition

\begin{tabular}{cccc}
\hline \multirow{2}{*}{$\begin{array}{c}\text { Liposome composition } \\
\text { (mol \% DPPC) }\end{array}$} & \multicolumn{2}{c}{ Rates of hydrolysis ${ }^{3}(\% / \mathrm{hr})$} & \\
\cline { 2 - 3 } & Saturated & Unsaturated & $P$ \\
\hline 40 & $4.22 \pm 1.08^{4}$ & $4.14 \pm 1.51$ & $\mathrm{NS}^{5}$ \\
50 & $3.75 \pm 0.73$ & $4.16 \pm 0.93$ & $\mathrm{NS}$ \\
60 & $3.08 \pm 0.29$ & $4.22 \pm 0.98$ & $\mathrm{NS}$ \\
\hline
\end{tabular}

${ }^{1} A_{1}: A_{2}=40: 60$.

${ }^{2}$ Dipalmitoyl phosphatidylcholine.

${ }^{3} n=4$.

4 Mean \pm S.E.

${ }^{5}$ Not significant $(P>0.05)$.

Table 5. Rates of hydrolysis of saturated and unsaturated phosphatidylcholines presented to lung lysosomal phospholipases $A$ (preparation III) ${ }^{1}$ in liposomes of varying composition

\begin{tabular}{ccrc}
\hline & \multicolumn{2}{c}{ Rates of hydrolysis $^{3}(\% / \mathrm{hr})$} & \\
\cline { 2 - 3 } $\begin{array}{c}\text { Liposome composition } \\
\text { (mol \% DPPC) }\end{array}$ & Saturated & Unsaturated & $P$ \\
\hline 5 & $8.90 \pm 0.88^{4}$ & $6.81 \pm 0.97$ & $\mathrm{NS}^{5}$ \\
50 & $2.68 \pm 0.30$ & $12.89 \pm 0.61$ & $<0.001$ \\
95 & $2.18 \pm 0.68$ & $9.71 \pm 0.68$ & $<0.001$ \\
\hline
\end{tabular}

${ }^{1} A_{1}: A_{2}=20: 80$.

${ }^{2}$ Dipalmitoyl phosphatidylcholine.

${ }^{3} n=4$.

${ }^{4}$ Mean \pm S.E.

${ }^{5}$ Not significant $(P>0.05)$.

Table 6. Effect of phosphatidylglycerol on the hydrolysis of phosphatidylcholines ${ }^{1}$ by lung lysosomal phospholipases $A^{2}$

\begin{tabular}{ccc}
\hline \multirow{2}{*}{$\begin{array}{c}\text { Liposome composition } \\
\text { (mol \% phosphatidylglycerol) }\end{array}$} & \multicolumn{2}{c}{ Rates of hydrolysis ${ }^{3}(\% / \mathrm{hr})$} \\
\cline { 2 - 3 } & Saturated & Unsaturated \\
\hline 0 & $7.92 \pm 1.78^{4}$ & $6.87 \pm 2.79$ \\
10 & $3.16 \pm 0.58$ & $6.58 \pm 0.37$ \\
$P$ & $<0.05$ & $\mathrm{NS}^{5}$ \\
\hline
\end{tabular}

${ }^{1}$ Fifty mol \% dipalmitoyl phosphatidylcholine liposomes.

${ }^{2}$ Preparation I, $A_{1}: A_{2}=60: 40$.

${ }^{3} n=4$.

4 Mean \pm S.E.

${ }^{5}$ Not significant $(P>0.05)$

toyl phosphatidylcholine liposomes, with preparation I, is shown in Table 6.

\section{DISCUSSION}

The different rates of hydrolysis of saturated and unsaturated phosphatidylcholines could be due to the chemical differences between the molecules or to a marked physical difference known to exist between the substrate liposomes. Dipalmitoyl phosphatidylcholine is solid in liposomes at $37^{\circ} \mathrm{C}$, the temperature of its transition to the fluid state being $41.4^{\circ} \mathrm{C}$ (26). The transition temperature for egg phosphatidylcholine, on the other hand, is near $-10^{\circ} \mathrm{C}(8)$, so this lipid is fluid in liposomes. When the dipalmitoyl species is diluted with egg phosphatidylcholine, its transition broadens, and the temperature of the transition is lowered until at compositions of less than about $70 \mathrm{~mol} \%$ dipalmitoyl phosphatidylcholine the lipid is fluid at $37^{\circ} \mathrm{C}(23)$. Those mixtures that are below the transition temperature are probably mosaics composed of areas of solid dipalmitoyl and fluid unsaturated phosphatidylcholine. Above that temperature, there will be limited miscibility of the fluid phases $(24,38)$.

The results with liposomes containing $5 \mathrm{~mol} \%$ dipalmitoyl phosphatidylcholine show that chemically the saturated species is susceptible to attack by phospholipases $A$ (Table 3 ), although perhaps phospholipase $A_{2}$ attacks less readily than $A_{1}$ (Table 5). However, the physical condition of the liposomes does affect the rate of hydrolysis of the saturated molecules (Tables 3 to 5). As the proportion of saturated molecules is increased, the solidity of the liposomes increases, and the rate of hydrolysis of dipalmitoyl phosphatidylcholine falls. Similar changes in enzyme activity caused by alterations in the fluidity of lipids have been described, but only for nonlysosomal phospholipases $(18,19,28,41)$.

Preparations of pulmonary surfactant contain 40 to $60 \%$ disaturated phosphatidylcholine $(15,22)$. It is difficult to obtain intracellular surfactant free of contaminating lipids, but it must certainly contain more than $60 \%$ disaturated phosphatidylcholine. If this is the composition of the lamellae, then those phosphatidylcholine molecules remaining unsaturated will be attacked preferentially by the lamellar body phospholipase $A_{2}$ (Table 5), whereas the phospholipase $A_{1}$ will attack the dipalmitoyl molecules as well (Tables 3 and 4). The presence of phosphatidylglycerol, which constitutes up to $10 \%$ of surfactant, could modify this picture. Phosphatidylglycerols are freely miscible with phosphatidylcholines of similar fatty acid composition (10), so they do not affect fluidity, but unlike phosphatidylcholines they are negatively charged and thus alter the charge of the lamellae (or substrate liposomes). Table 6 shows the inhibitory effect of the addition of $10 \mathrm{~mol} \%$ phosphatidylglycerol on the hydrolysis by enzyme preparation I of saturated molecules in liposomes of $50 \mathrm{~mol} \%$ dipalmitoyl phosphatidylcholine.

The de novo pathways of phosphatidylcholine synthesis in the lung produce principally unsaturated molecules $(32,33,35)$ which must be converted to the dipalmitoyl species by a remodeling process $(6,37)$. This starts with phospholipase $A_{2}$ action on the unsaturated lipid yielding 1-palmitoyl-2-lysophosphatidylcholine which can be turned into the required product by the introduction of a palmitoyl residue at the vacant 2-position of molecule. The lung has two mechanisms for achieving this, either transfer from palmitoyl-CoA (reacylation) or from a second molecule of the palmitoyl lysophosphatidylcholine (transacylation). The preferential attack of lamellar body phospholipase $A_{2}$ on unsaturated phosphatidylcholine yields as the major product 1-palmitoyl-2lysophosphatidylcholine, the substrate for the remodeling enzymes. The principal site of remodeling processes is probably the endoplasmic reticulum, where many enzymes of the de novo pathway and the reacylating enzyme (lysophosphatidylcholine: acyl-CoA acyltransferase, EC 2.3.1.23) are found. The transacylating enzyme (lysophosphatidylcholine:lysophosphatidylcholine acyltransferase, EC 2.3.1.-) is, however, free in the cytosol, and it has been suggested (1) that it might be able to act on the products of lamellar body phospholipase $A_{2}$ action in situ, although the mechanism by which this might occur is unclear. In any case, it seems probable that the lysolipid will be returned to the synthetic pathways for remodeling. Failure to remodel effectively results in a form of respiratory distress in which normal amounts of surfactant phosphatidylcholine are produced, but with a decreased proportion of saturated molecules (27).

Clearly, the presence of phospholipases in lamellar bodies rep- 
resents a threat to the integrity of the surfactant; phospholipase activity might be a contributory factor in the etiology of the respiratory distress syndrome of the newborn. The deficiency of phosphatidylglycerol in the lung lipids of infants with respiratory distress (14) would exacerbate any such catabolic action of the phospholipases.

\section{CONCLUSION}

These studies of lysosomal phospholipases $\mathrm{A}$ from rabbit lung have shown significant changes in the rate of catabolism of dipalmitoyl phosphatidylcholine in response to changes in the proportions of saturated and unsaturated phosphatidylcholine molecules in the substrate liposomes. The data suggest that the phospholipase $A_{2}$ of lamellar bodies will preferentially hydrolyze unsaturated molecules and might thus assist in surfactant synthesis.

Phospholipases $A_{1}$ and $A_{2}$ in lamellar bodies also represent a threat to the integrity of the surfactant and thus a possible contributory factor to the respiratory distress syndrome of the newborn. Phosphatidylglycerol, a constituent of surfactant, is inhibitory to these enzymes.

\section{REFERENCES AND NOTES}

I. Baranska, J., and van Golde, L. M. G.: Role of lamellar bodies in the biosynthesis of phosphatidylcholine in mouse lung. Biochim. Biophys. Acta, 488: 285 (1977).

2. Barrett, A. J.: Lysosomal acid proteinase of rabbit liver. Biochem. J., 104: 601 (1967).

3. Barrett, A. J., and Heath, M. F.: Lysosomal enzymes. In: J. T. Dingle: Lysosomes: A Laboratory Handbook. 2nd ed. pp. 19-145 (North-Holland Publishing Co., Amsterdam, 1977).

4. Bensch. K.. Schaefer, K., and Avery, M. E.: Granular pneumocytes: electron microscopic evidence of their exocrinic function. Science, 145: 1318 (1964).

5. Bligh, E. G., and Dyer, W. J.: A rapid method of total lipid extraction and purification. Can. J. Biochem. Physiol., 37: 911 (1959).

6. Brumley, G., and van den Bosch, H.: Lysophospholipase-transacylase from rat lung: isolation and partial purification. J. Lipid Res., 18: 523 (1977).

7. Campbell, P. N., and Sargent, J. R.: Miscellaneous techniques. 1. Estimation of total protein by the method of Lowry et al. (195I). In: P. N. Campbell, J. R. Sargent: Techniques in Protein Biosynthesis. Vol. 1, pp. 299-300 (Academic Press, Inc.. New York, 1967).

8. Chapman. D.: Phase transitions and fluidity characteristics of lipids and cell membranes. Q. Rev. Biophys., 8: 185 (1975).

9. Chevalier, G., and Collet, A. J.: In vivo incorporation of choline- ${ }^{-} \mathrm{H}$, leucine-'H and galactose ${ }^{3} \mathrm{H}$ in alveolar type II pneumocytes in relation to surfactant synthesis. A quantitative radioautographic study in mouse by electron microscopy. Anat. Rec., 174: 289 (1972).

10. Findlay, E. J., and Barton, P. G.: Phase behaviour of synthetic phosphatidylglycerols and binary mixtures with phosphatidylcholines in the presence and absence of calcium ions. Biochemistry, 17: 2400 (1978).

11. Franson, R., Beckerdite, S., Wang. P.. Waite, M., and Elsbach, P.: Some properties of phospholipases of alveolar macrophages. Biochim. Biophys. Acta, 296: 365 (1973).

12. French. J. A., and Anderson. D. W.: Separation and quantitative recovery of lipid classes; a convenient thin-layer chromatographic method. J. Chromatogr. 80: $133(1973)$.

13. Gandy, G., Jacobson, W, and Gairdner, D.: Hyaline membrane disease. I: Cellular changes. Arch. Dis. Child., 45: 289 (1970).

14. Hallman, M., and Gluck, L.: Phosphatidylglycerol in lung surfactant. III. Possible modifier of surfactant function. J. Lipid Res., 17: 257 (1976).

15. Harwood, J. L., Desai, R., Hext, P., Tetley, T., and Richards, R.: Characterization of pulmonary surfactant from ox, rabbit, rat and sheep. Biochem. J., 151: 707 (1975).

16. Heath, M. F., Gandy, G., and Jacobson. W.: Lysosomes in the lung. In: J. T Dingle, R. T. Dean: Lysosomes in Biology and Pathology. Vol. 5, pp. 33-58 (North-Holland Publishing Co., Amsterdam, 1976).

17. Heath, M. F., and Jacobson, W.: Phospholipases $A_{1}$ and $A_{2}$ in lamellar inclusion bodies of the alveolar epithelium of rabbit lung. Biochim. Biophys. Acta, 441: 443 (1976).

18. Jain, M. K., and Cordes, E. H.: Phospholipases. I. Effect of $n$-alkanols on the rate of enzymatic hydrolysis of egg phosphatidylcholine. J. Membrane Biol., 14: 101 (1973).

19. Jain. M. K., and Cordes. E. H.: Phospholipases. II. Enzymatic hydrolysis of lecithin: effects of structure. cholesterol content, and sonication. J. Membr. Biol., 14: 119 (1973).

20. Kikkawa, Y.. Motoyama, E. K., and Cook. C. D.: The ultrastructure of the lungs of lambs. The relation of osmiophilic inclusions and alveolar lining layer to fetal maturation and experimentally produced respiratory distress. Am. J. Pathol., 47: 877 (1965).

21. Kikkawa, Y., Yoneda, K., Smith, F., Packard, B., and Suzuki, K.: The type II epithelial cells of the lung. II. Chemical composition and phospholipid synthesis. Lab. Invest., 32: 295 (1975).

22. King, R. J.: The surfactant system of the lung. Fed. Proc., 33: 2238 (1974)

23. Knight, C. G., Cowper, J. J., and Page Thomas, D. P.: (unpublished results).

24. Lee, A. G.: Lipid phase transitions and phase diagrams. 11. Mixtures involving lipids. Biochim. Biophys. Acta. 472: 285 (1977).

25. Lowry, O. H., Rosebrough. N. J., Farr, A. L., and Randall. R. J.: Protein measurement with the Folin phenol reagent. J. Biol. Chem., 193: 265 (1951)

26. Mabrey, S., and Sturtevant, J. M.: Investigation of phase transitions of lipids and lipid mixtures by high sensitivity differential scanning calorimetry. Proc. Natl. Acad. Sci. U. S. A., 73: 3862 (1976).

27. Ogawa, Y., Okamoto, T.. Fukuda, M., Hiratani, Y., and Ogawa, J.: Estimation of surfactant lecithin in amniotic fluid and prediction of respiratory distress syndrome. Biol. Neonate, 28: 18 (1976).

28. Op den Kamp. J. A. F., de Gier, J., and van Deenen. L. L. M.: Hydrolysis of phosphatidylcholine liposomes by pancreatic phospholipase $A_{2}$ at the transition temperature. Biochim. Biophys. Acta, 345: 253 (1974).

29. Pennington, R. J.: Biochemistry of dystrophic muscle. Mitochondrial succinatetetrazolium reductase and adenosine triphosphatase. Biochem. J., 80: 649 (1961).

30. Phillips, A. H., and Langdon, R. G.: Hepatic triphosphopyridine nucleotidecytochrome c reductase: isolation, characterization, and kinetic studies. J. Biol. Chem., 237: 2652 (1962).

31. Porteous, J. W., and Clark, B.: The isolation and characterization of subcellular components of the epithelial cells of rabbit small intestine. Biochem. J., 96: 159 (1965).

32. Possmayer, F., Duwe, G., Hahn, M., and Buchnea. D.: Acyl specificity of CDP choline: 1,2-diacylglycerol cholinephosphotransferase in rat lung. Can. J. Biochem., 55: 609 (1977).

33. Rooney, S. A., and Wai-Lee, T. S.: Cholinephosphotransferase from rabbit lung microsomes. An improved assay and specificity towards exogenous diacylglycerols. Lung, 154: 201 (1977).

34. Ryan, U. S., Ryan. J. W., and Smith, D. S.: Alveolar type II cells: studies on the mode of release of lamellar bodies. Tissue Cell. 7: 587 (1975).

35. Sarzala, M. G., and van Golde, L. M. G.: Selective utilization of endogenous unsaturated phosphatidylcholines and diacylglycerols by cholinephosphotransferase of mouse lung microsomes. Biochim. Biophys. Acta, 441: 423 (1976).

36. Sorokin, P.: A morphologic and cytochemical study on the great alveolar cell. J. Histochem. Cytochem., 14: 884 (1967).

37. van Golde. L. M. G.: Metabolism of phospholipids in the lung. Am. Rev, Respir. Dis., 114: 977 (1976).

38. Ververgaert, P. H. J. T., and Verkley, A. J.: Freeze-etching and membranes. In: R. Paoletti, G. Porcellati, G. Jacini: Lipids. Vol. I, pp. 181-185 (Raven Press, New York, 1976)

39. Waite, M.. Griffin, H. D., and Franson, R.: The phospholipases A of lysosomes. In: J. T. Dingle, R. T. Dean: Lysosomes in Biology and Pathology, Vol. 5, pp. 257-305 (North-Holland Publishing Co., Amsterdam, 1976).

40. Watkins, J. C.: The surface properties of pure phospholipids in relation to those of lung extracts. Biochim. Biophys. Acta, 152: 293 (1968).

41. Wilschut, J. C.. Regts, J., Westenberg. H., and Scherphof, G.: Action of phospholipases $\mathrm{A}_{2}$ on phosphatidylcholine bilayers. Effects of the phase transition, bilayer curvature and structural defects. Biochim. Biophys. Acta, 508: 185 (1978).

42. Worwood, M., Dodgson, K. S., Hook, G. E. R., and Rose, F. A.: Problems associated with the assay of arylsulphatases $A$ and $B$ of rat tissues. Biochem. J., 134: 183 (1973).

43. The specific radioactivities given in "Materials and Methods" in Ref. 17 should be as follows: for $13 \mathrm{Ci} /$ mole, read $0.25 \mathrm{Ci} /$ mole, and for $25 \mathrm{Ci} / \mathrm{mole}$, read $0.50 \mathrm{Ci} /$ mole.

44. Dr. Heath is a Sir Halley Stewart Research Fellow.

45. Dr. Jacobson is a Sir Halley Stewart Research Professor.

46. Requests for reprints should be addressed to: Dr. M. F. Heath, Strangeways Research Laboratory, Wort's Causeway, Cambridge CB1 4RN, England.

46. This research was supported by the Sir Halley Stewart Trust and by the Medical Research Council, who defrayed part of the expenses.

47. Received for publication Dec 13, 1978.

48. Accepted for publication May 15, 1979. 